\section{NOVA TELLVS}

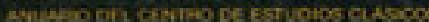

Nova Tellus

ISSN: 0185-3058

novatelu@servidor.unam.mx

Centro de Estudios Clásicos

México

López Cruz, Paula

La fábula de Menenio Agripa (Liv., II, 32-33)

Nova Tellus, vol. 29, núm. 2, 2011, pp. 117-128

Centro de Estudios Clásicos

Distrito Federal, México

Disponible en: http://www.redalyc.org/articulo.oa?id=59122571004

- Cómo citar el artículo

- Número completo

- Más información del artículo

- Página de la revista en redalyc.org

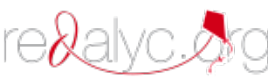

Sistema de Información Científica

Red de Revistas Científicas de América Latina, el Caribe, España y Portugal

Proyecto académico sin fines de lucro, desarrollado bajo la iniciativa de acceso abierto 


\title{
La fábula de Menenio Agripa (Liv., II, 32-33)
}

\author{
Paula LÓPEz CRUZ \\ Universidad Nacional Autónoma de México \\ paula@unam.mx
}

RESUMEN: Durante el acontecimiento conocido como la primera secesión de la plebe del año 494 a. C., Menenio Agripa pronunció en el campamento del Monte Sacro y ante los plebeyos un discurso que contenía la fábula conocida como Del estómago y los miembros para persuadir a aquéllos de que regresaran a Roma. Tito Livio narra ese acontecimiento en su obra $A b$ urbe condita (II, 32, 8-12), pero sólo registra la fábula mencionada, sin dar otros detalles del discurso. El estudio tiene como objeto analizar ese texto con base en la preceptiva retórica, centrándose, por un lado, en revisar si la recreación literaria del episodio fue adecuada para la narración del exemplum y, por otro, en comprender qué interés pudo mover al autor a narrar únicamente la fábula.

\section{Menenius Agrippa's Fable \\ (Liv., II, 32-33)}

ABSTRACT: In 494 a. C. in the course of the first seccesion of the plebs, Menenius Agrippa delivered a speech to the plebeians at the camp at Monte Sacro containing the fable The Belly and the Limbs to persuade them to return to Rome. Livy recounts this event in his work $A b$ urbe condita (II, 32, 8-12), but he only reports the fable without giving further details of the speech. This study is aimed at analyzing the text on the basis of the rhetorical precepts. On the one hand, it tries to find out if the literary form of the historical episode fits the form of an exemplum, and, on the other, it looks for the author's purpose behind the choice of recounting solely the fable.

Palabras Clave: Menenio Agripa, Tito Livio, fábula, retórica.

KeYwords: Menenius Agrippa, Livy, fable, rhetoric.

FECHA DE RECEPCIÓN: 17 de noviembre de 2011.

FECHA DE ACEPTACIÓN: 9 de enero de 2012. 


\title{
La fábula de Menenio Agripa (Liv., II, 32-33)
}

\author{
Paula LÓPEZ CRUZ
}

En el año 494 a. C. tuvo lugar un hecho importante para la historia de Roma: la primera secesión de los plebeyos. Según cuenta Tito Livio, muchos de ellos ya habían sido reducidos a esclavitud, ${ }^{1}$ pues los intereses tan altos y las constantes guerras no les habían permitido pagar sus deudas. Al no obtener, de parte de los cónsules y senadores, una solución a su problema, deciden aprovechar el anuncio de la guerra con los ecuos para apartarse de Roma y establecer su campamento en el Monte Sacro. ${ }^{2}$

Ante esta situación tan grave, se decide enviar a Menenio Agripa como legado al campamento del Monte Sacro con el objetivo de lograr la concordia de los ciudadanos. ${ }^{3}$ Por Dionisio de Halicarnaso sabemos que Menenio propuso en el Senado enviar al Monte Sacro una comisión formada por los hombres en quienes los plebeyos tuvieran más confianza; ${ }^{4}$ asimismo, pidió que estos hombres tuvieran "plenos poderes para llegar con los plebeyos a una solución de la revuelta en los términos que a ellos mismos les pareciesen justos, sin necesidad de dar previamente cuenta de ellos al Senado". 5 Tanto Menenio como los senadores sabían que los plebeyos

\footnotetext{
${ }^{1}$ El plebeyo Lucio Junio Bruto, en el discurso que pronuncia cuando los embajadores del Senado han llegado al campamento del Monte Sacro, describe la situación que vivían los romanos reducidos a servidumbre (D. H., VI, 79, 2-3): "a ninguno de nosotros le queda allí [en Roma] un lote de tierra, ni un hogar de sus antepasados, ni sacrificios comunes ni una posición, como en una patria... Algunos de estos bienes los han destruido las muchas guerras, otros los consumió la escasez de alimentos y otros los han arrebatado esos arrogantes prestamistas para quienes hemos acabado, desgraciados, obligados a trabajar las tierras, cavando, plantando, arando y cuidando rebaños, compañeros de esclavitud de sus prisioneros de guerra, atados unos con cadenas, otros con grillos y otros con collares y bloques de metal como las fieras más salvajes. Y no hablo de los malos tratos, ultrajes, azotes, trabajos de sol a sol y todas las demás crueldades, insultos y arrogancias que hemos soportado".

${ }^{2}$ Liv., II, 32, 1-4.

${ }^{3}$ Livio (II, 32, 8) no especifica quiénes toman la decisión de enviarlo.

${ }^{4}$ D. H., VI, 47-69.

${ }^{5}$ D. H., VI, 56, 5.
} 
pedirían la abolición de las deudas. Al principio, los senadores se oponen a la propuesta, pero al final designan a diez hombres para resolver el conflicto, entre los que se encontraba el propio Menenio.

Ante los plebeyos reunidos en el campamento, tienen lugar varias intervenciones, tanto de los legados como de los plebeyos. Al final, y a punto de que éstos desistieran en su intento por llegar a un acuerdo, Menenio interviene para calmar los ánimos y comunicar la decisión tomda por los diez legados de condonar las deudas; ${ }^{6}$ también les anuncia que éstos y sus familias quedan como garantía de que esta vez no los engañarán. ${ }^{7}$ Luego, Menenio les cuenta una fábula a la manera de Esopo. Por último, para acabar de persuadirlos, recurre "a los lamentos y a las desgracias que caerían sobre la ciudad" y sobre los sublevados. ${ }^{8}$ De inmediato, los plebeyos piden regresar a Roma, pero Bruto, uno de los plebeyos al frente del campamento, se adelanta para solicitar que se les conceda la creación de magistrados "sin otro poder que el de ayudar a los plebeyos que hayan sido objeto de injusticia o violencia y el de no permitir que nadie se vea privado de sus derechos". ${ }^{9}$ Es así como se crea la magistratura de "tribuno de la plebe".

De toda esta historia, que es larga en la versión de Dionisio de Halicarnaso, Tito Livio decidió transmitir solamente la narración de la fábula y pasar en silencio hechos tan importantes como la comisión de diez hombres y la condonación de deudas, además de restarle protagonismo a Menenio Agripa al no contar cómo se gestó la solución de la grave crisis que se vivió en Roma.

${ }^{6}$ D. H., VI, 83, 4-5: “que todos los que tengan deudas y no puedan pagarlas queden libres de ellas, y si algunos, por haberles vencido la fecha de pago, ven ya sus personas sometidas a la esclavitud prescrita por las leyes, establecemos que también éstos queden en libertad. Y también queremos que queden libres cuantos, condenados en juicios particulares, han sido entregados a sus demandantes, y dejamos sin validez sus condenas. Con respecto a las deudas futuras, quede establecido, después de sancionarlo como ley, lo que vosotros, plebeyos, y el Senado decidáis en común deliberación”.

${ }^{7}$ Dionisio (VI, 28, 2) cuenta que Servilio había prometido a los plebeyos que, una vez terminada la guerra, "entonces ya considerarían la manera de establecer una forma de gobierno equitativa, imparcial y provechosa para todos, en la que ni los pobres conspiraran contra las haciendas de los ricos, ni éstos insultaran a los más humildes,... en la que hubiera una asistencia estatal para los pobres y también una ayuda proporcionada para los prestamistas"; pero al terminar la guerra, Servilio no pudo hacer cumplir su promesa, y, en lugar de ello, el cónsul Apio Claudio reanuda los juicios por deudas, sentenciando con mayor dureza.

${ }^{8}$ D. H., VI, 87, 1.

${ }^{9}$ D. H., VI, 87, 3. 
Livio relata lo siguiente: Después del retiro de los plebeyos al Monte Sacro, en la ciudad se viven momentos de terror porque tanto los plebeyos que se habían quedado como los patricios temían que la violencia estallara de una u otra parte. Éstos deliberan sobre la situación y deciden que debía conseguirse a cualquier precio la concordia de los ciudadanos. Por ello, envían como legado a Menenio Agripa, hombre elocuente y querido de la plebe por ser de origen plebeyo. Éste, al entrar en el campamento, se limita a contarles lo que sucedió en el cuerpo del hombre cuando no había acuerdo entre sus miembros, pues cada uno tenía su propio pensamiento. En esa época aconteció que los miembros del cuerpo tramaron una conspiración contra el estómago, porque pensaban que por estar en medio del cuerpo no hacía nada y sólo se dedicaba a disfrutar del alimento que recibía por el trabajo y esfuerzo de los demás. Indignados por esto, conspiraron para que las manos no llevaran alimento a la boca, para que ésta no lo aceptara y los dientes no lo trituraran; de esta manera imaginaron que podrían someter al estómago por hambre, pero pronto se dieron cuenta de que todo el cuerpo adelgazó extremadamente. Hasta entonces, los miembros del cuerpo entendieron con toda claridad cuál era la verdadera función del estómago: él también los alimentaba al enviarles, por igual, la sangre que elaboraba por medio de la digestión de los alimentos que recibía. Livio añade que, haciendo esta comparación entre la sedición interna del cuerpo y la ira de la plebe contra los patricios, Menenio logró doblegar las mentes de aquellos hombres. De inmediato se empezó a tratar sobre la reconciliación y se acordó la creación de los tribunos de la plebe, cuya finalidad sería auxiliar a los plebeyos ante las decisiones de los cónsules. ${ }^{10}$

La razón de relatar tan poco de este acontecimiento la encontramos en el prefacio general de la obra. Ahí Livio precisa que el objetivo principal de escribir la historia de Roma es instruir a los ciudadanos, y para ello busca presentar el modo de vida de los antiguos romanos que forjaron la grandeza de Roma, es decir, sus costumbres, sus actos y las decisiones que pudieran servir como ejemplos de conducta, con la intención de que sus contemporáneos imitaran las conductas buenas y evitaran las malas, en beneficio tanto propio como de la urbe. ${ }^{11}$ Así, su pensamiento se inserta en el grupo de romanos tradicionalistas, que consideraban que el pasado podía servir de modelo para el presente y que la imitación de las proezas

\footnotetext{
${ }^{10}$ Liv., II, 32-33.1.

${ }^{11}$ Liv., Praef., 10.
} 
de los hombres ilustres garantizaría la continuidad de la grandeza romana, pues suponían que era la mejor manera de solucionar los problemas de Roma. No le interesó hacer una historia de las instituciones políticas o de las luchas sociales, sino rememorar el pasado en función de los intereses de la aristocracia romana.

Con esta idea en mente, Livio prefirió relatar algunos hechos de este episodio y omitir otros. Para realizar lo anterior, el autor busca comprender la naturaleza de la causa, determinar de qué manera es defendible e insertar su discurso de manera adecuada y de acuerdo con el efecto persuasivo que pretende en un contexto determinado (elementos pertenecientes a la operación retórica llamada intellectio). El orador debe examinar el tema que va a tratar, las posibilidades de su desarrollo ante su auditorio, el contexto en el que va a situar el discurso, los conocimientos y las expectativas de los oyentes, el alcance de su discurso y las posibilidades de influencia de éste en los oyentes. ${ }^{12}$ Es el primer momento en el que el autor ha de activar el principio del decorum o aptum. Este principio fundamental consiste en la perfecta armonía del contenido con la forma de expresarlo, atendiendo al auditorio que lo va a recibir, al fin que se pretende conseguir y al contexto de su recepción. El decorum exige, además, "la coherencia del orador y su credibilidad porque la audiencia requiere una correspondencia entre expresiones y acciones (lo dicho y lo hecho), así como la máxima aproximación entre palabras, pronunciadas o escritas, y realidad". ${ }^{13}$

En el sistema de los estilos, el decorum exigía la adecuación del estilo al asunto. En el Orator (69), Cicerón dice que "cuantos son los oficios del orador, tantos son los géneros del decir: el simple en el probar, el templado en el deleitar, el vehemente en el doblar". ${ }^{14}$ Para el caso que nos atañe, Livio debía lograr, por un lado, un estilo sencillo porque se trataba de reconciliar a los plebeyos con los patricios; por el otro, un estilo templado para deleitar a su público, y, por último, credibilidad ante sus oyentes.

De acuerdo con Perelman, el auditorio está compuesto por el conjunto de las personas en las que el orador quiere influir. ${ }^{15}$ A esta definición, Tomás

\footnotetext{
${ }^{12}$ Albaladejo, 2000, p. 7.

${ }^{13}$ Ruiz de la Cierva, 2008, p. 35.

${ }^{14}$ En XII, 10, 59, Quintiliano dice: "para enseñar se necesita agudeza; para conciliar, suavidad, y para mover, fuerza".

${ }^{15}$ Perelman y Olbrechts-Tyteca, apud Albaladejo, 1994, p. 9.
} 
Albaladejo añade que "el orador puede intentar influir... también en esos otros receptores a los que no está, en principio, destinado el discurso". ${ }^{16}$ Por ello hace la distinción entre destinatario primario y otro secundario. A mi modo de ver, la fábula de Menenio, como discurso deliberativo, tiene un destinatario primario: los miembros de la asamblea; y nuestro autor, su propio destinatario primario: sus contemporáneos patricios en los que quiere influir. Por tal motivo se puede pensar que la fábula liviana persigue dos fines: por un lado, hacer creer que Menenio logró persuadir a los plebeyos de que regresaran a Roma; por otro, convencer a sus contemporáneos de que los patricios (patres) en la ciudad, como el estómago en el cuerpo, desempeñan una función vital. Empatar ambos fines fue la tarea principal de nuestro autor.

Empero, como se trata de un discurso deliberativo en una obra de género demostrativo, el verdadero interés de Livio está en crear una opinión favorable a la posición que defiende en sus destinatarios, de quienes, aunque no aprueban o rechazan una propuesta, se espera que en un futuro tomen decisiones acordes con lo que el orador quiere inculcarles. ${ }^{17} \mathrm{~A}$ ello se debe que, en este episodio, no mencione todo lo relacionado con las deudas, que fue el origen de la sublevación plebeya, y con la condonación de las mismas, gracias a lo cual los plebeyos decidieron regresar a Roma, según Dionisio. Sólo le importó narrar la parte concerniente a la importancia de los patres en la ciudad. En el fondo está diciendo a los romanos que éstos, como integrantes del órgano de gobierno, cumplen una función muy importante para la ciudad.

Quintiliano dice que el exordio no siempre tiene cabida, porque es ocioso cuando no se necesita preparar a los oyentes, como puede suceder en los discursos del género deliberativo; pero siempre ha de haber una entrada breve, "pues el orador no ha de comenzar bruscamente, ni por donde le plazca, ya que en todo asunto hay algo que es lo primero". ${ }^{18}$

Con el exordio, el orador debe lograr que sus oyentes estén dispuestos a escucharlo con atención, benevolencia y docilidad. De acuerdo con este precepto, Menenio no debió empezar la narración de la fábula sin una previa entrada.

Livio, al decir que se envió a Menenio por ser "un hombre elocuente y querido del pueblo por su origen plebeyo", suple el exordio, pues con esas

\footnotetext{
${ }^{16}$ Id.

${ }^{17}$ Albaladejo, 2001, p. 337.

${ }^{18}$ Quint., III, 8, 6.
} 
palabras hace pensar que los plebeyos, al verlo llegar al campamento, lo consideraron un hombre digno de ponerle atención por el parentesco que los unía a él; es decir que Livio se basa, de manera indirecta, en el ethos del orador para que la atención, la benevolencia y la docilidad le sean otorgadas por parte de su auditorio y pueda relatar la fábula.

Con esas palabras, Livio recrea un contexto favorable en el que hablará Menenio, sin necesidad de un exordio o entrada breve como prescribe Quintiliano. No obstante, resulta bastante extraño imaginar que Menenio entró en el campamento y empezó a hablar. A no ser que Livio quisiera dar la impresión de que los plebeyos estaban a la expectativa de un enviado, de manera que al ver llegar a Menenio se reunieron espontáneamente en torno suyo con el interés de escucharlo. La asamblea (contio) debería haber sido convocada con anticipación, tal como sucede en la narración de Dionisio. ${ }^{19}$

Asimismo, Livio prescinde de la narración de los hechos que constituyen la causa y que sirven para proporcionar información al auditorio. Es clara la razón de por qué la omite: no tiene interés en hablar de las deudas. Lo adecuado, en este caso, es callarlo.

Menenio pasa directamente a la argumentación, y de ésta elige una prueba que le ayudaría a persuadir más fácilmente a un auditorio: la fábula. Livio construye su texto sobre hechos determinados y conocidos por todos. En este proceso, la inventio consiste en hacer una selección de lo que parece pertinente o adecuado a su interés por dejar una enseñanza, pero que al mismo tiempo resulte verosímil.

La fábula es un tipo de exemplum, que sirve como prueba eficaz de lo que el orador quiere demostrar. Quintiliano aconseja usarla sobre todo ante hombres rústicos "que oyen las cosas que son inventadas con tanta sencillez, y capturados por el agrado fácilmente deciden de acuerdo con aquellas cosas por las que son deleitados". ${ }^{20}$

La eficacia de la fábula, como estrategia argumentativa, se debe a la facilidad con que el orador puede llevar a su auditorio a establecer comparaciones entre la historia que se le relata y la realidad que vive.

Mediante la operación retórica de la inventio, Livio decide concentrar la narración de la fábula en cuatro ideas: 1) la acción de la fábula es ubicada en un tiempo remoto: cuando no había acuerdo entre los miembros del

\footnotetext{
${ }^{19}$ D. H., VI, 70, 2: "Después de esto, Sicinio convocó al pueblo en asamblea e invitó a los embajadores a exponer los motivos de su llegada".

${ }^{20}$ Quint., V, 11, 19.
} 
cuerpo; 2) la conspiración de los miembros contra el estómago; 3 ) todo el cuerpo resulta afectado por la conspiración, y 4) la comparación entre la sedición plebeya y la del cuerpo, dicha por nuestro autor. En cuanto al orden (dispositio) de los argumentos, Livio no alteró nada.

Dionisio de Halicarnaso cuenta la misma fábula en relación con el mismo asunto, pero presenta claras diferencias, sin contar con que lo hace más profusamente.

La primera diferencia entre la fábula de Livio y la de Dionisio estriba en que aquél presenta los hechos como sucedidos en un tiempo remoto: en una época en que en el hombre, como ser vivo, había desunión y desacuerdo porque cada miembro tenía una manera propia de hablar y de pensar. ${ }^{21}$ En cambio, Dionisio hace que Menenio parta de la suposición de lo que pasaría "si las partes del cuerpo humano llegasen a tener por sí solas percepción y voz propias". ${ }^{22}$ Es decir, se dirige al futuro, tiempo adecuado al género deliberativo.

En segundo lugar, Tito Livio escoge solamente a los miembros del cuerpo que intervienen en el acto de comer: las manos, que son las que llevan el alimento a la boca; la boca, que lo recibe; los dientes, que lo trituran, y el estómago, que lo digiere. Y son los tres primeros, las manos, la boca y los dientes, los únicos que se ponen de acuerdo para someter al estómago. En cambio, Dionisio hace participar a los pies, las manos, los hombros, la boca y la cabeza.

En tercer lugar, en la fábula de Livio las partes del cuerpo, indignadas de trabajar para el estómago, deciden conspirar contra él, que sólo disfruta de los placeres recibidos: las manos no llevarán el alimento a la boca, ésta no lo aceptará y los dientes no lo masticarán. En Dionisio, los miembros del cuerpo también conspiran contra el estómago.

A consecuencia de esta decisión, tomada por el enojo de la inequidad que vivían, los miembros y todo el cuerpo llegaron, conjuntamente, a una extrema consunción. Es entonces cuando los miembros se dan cuenta de la función del estómago. Por medio de un poliptoton (nec magis ali quam alere eum), Menenio aclara que el estómago es alimentado por los miembros, pero que éstos también son alimentados por aquél, pues les envía a todos ellos la sangre, que es fuente de nuestra vida y vigor, y la reparte por igual en las venas, después de haberla elaborado por medio de la

\footnotetext{
${ }^{21}$ Liv., II, 32, 9.

${ }^{22}$ D. H., VI, 86, 2.
} 
digestión. En cambio, en Dionisio, Menenio explica, mediante preguntas, que el cuerpo podría morir de hambre, si los miembros se negaran a hacer su trabajo; luego aclara lo que pasaría a un Estado si los hombres tomaran la misma actitud que los miembros del cuerpo, y hace énfasis en la importancia del Senado como administrador de los asuntos públicos.

Por último, en Livio, la narración de la fábula es breve y clara, no hay diálogo y su estilo es sencillo, apto para los oyentes a quienes va dirigida. En efecto, con la frase "el lenguaje arcaico y tosco propio de aquellos tiempos", ${ }^{23}$ Livio indica a los destinatarios de su obra que no debían esperar, en esa época remota, un discurso según los cánones de la retórica. En cambio, el relato que nos ofrece Dionisio, si bien más elaborado, no es propiamente una fábula compuesta a la manera de Esopo, aunque diga que Menenio la narró como tal. ${ }^{24}$

En conclusión, la comparación que Livio (como narrador) establece entre el cuerpo y la ciudad, en donde los miembros que intervienen en la fábula (la boca, las manos y los dientes) representan a los ciudadanos, y el estómago a los patres, permite que los plebeyos relacionen el caos en el cuerpo, desatado por la negativa de los miembros a alimentarlo, con el caos en la ciudad, originado por la negativa de los plebeyos no sólo a regresar a Roma sino a tomar las armas, es decir, a hacer el trabajo que les corresponde.

En la parte donde Livio presenta por vez primera el problema de las deudas, los plebeyos se niegan a ir a la guerra contra los volscos, argumentando que sólo los patricios debían tomar las armas, puesto que eran ellos quienes se quedaban con los premios de las victorias. ${ }^{25}$ Sin duda, esta idea la tenían en mente los oyentes de Livio, de manera que podían relacionarla con la imagen que los miembros del cuerpo tenían del estómago como el que se dedicaba a disfrutar del trabajo de los demás.

No debió ser extraño para los oyentes escuchar una nueva versión de la fábula, pues en la antigüedad fue común que, en sus años de aprendizaje, los romanos imitaran modelos "para recrear textos a partir de otros textos, para igualar el estilo o contraponerse a ellos o emularlos". ${ }^{26}$

Así pues, en su afán por dejar ejemplos de conducta, Livio sólo presenta la parte del exemplum: la fábula, que es un género apropiado para

\footnotetext{
${ }^{23}$ Liv., II, 32, 8.

${ }^{24}$ D. H., VI, 83, 2.

${ }^{25}$ Liv. II, 24, 2.

${ }^{26}$ Coviello, 2006, pp. 116-117.
} 
transmitir los valores relativos a la conducta. A cada miembro de la ciudad le corresponde un trabajo; a los patres, la función especial de dirigir.

La selección de lo que le pareció pertinente a su causa ha de entenderse como una construcción interpretativa de los hechos de origen y los silencios (o ausencias), como el deseo consciente de escamotearlos. Esta construcción, en donde sólo tiene cabida la fábula, adquiere un sentido diferente, convincente, pero manipulador, a tal punto que el conflicto de las deudas desaparece, y el problema de la ciudad por la ausencia de los plebeyos, aunque fue muy grave, queda relegado. Asimismo, la fábula, al subrayar la importancia de la función del estómago-los patres, valida la posición rectora de éstos en la sociedad romana.

Aunque se aparta bastante de la verdad, ocultando información de este episodio - que, por lo demás, sus oyentes debieron conocer muy bien,$-{ }^{27}$ logró recrear una auténtica fábula compuesta al modo de Esopo, como dijo Dionisio de Halicarnaso, mediante la cual pudo alcanzar los fines retóricos que perseguía.

\section{BIBLIOGRAFÍA}

\section{Fuentes}

CICÉRON, L'orateur, du meilleur genre d'orateurs, texte établi et traduit par Albert Yon, Paris, Les Belles Lettres, 1964.

Dionisio de Halicarnaso, Historia antigua de Roma, libros VII-IX, traducción y notas de Almudena Alonso y Carmen Seco, Madrid, Gredos, 1989.

QuintiLIEN, Institution Oratoire, texte établi et traduit par Jean Cousin, Paris, Les Belles Lettres, t. II, livres II et III, 1976; t. III, livres IV-V, 1976; t. VII, livres XII, 1980.

TITI Livi, A $b$ Vrbe Condita, t. I (libri I-V), recognoverunt et adnotatione critica instruxerunt C. Flamstead Walters et R. Seymour Conway, Oxonii, E Typographeo Clarendoniano, 1970 (Scriptorum Classicorum Bibliotheca Oxoniensis).

Tito Livio, Los orígenes de Roma, libros I-V, edición de Maurilio Pérez González, Madrid, AKAL, 1989 (Clásicos Latinos).

\section{Estudios}

AlbaladeJo, Tomás, "Sobre la posición comunicativa del receptor del discurso retórico", Castilla. Estudios de literatura, 19, 1994, pp. 7-16.

\footnotetext{
${ }^{27}$ Liv., Praef., 2.
} 
_, "La retórica en el umbral del siglo xxI: posibilidades, límites, propuestas", en $E l$ horizonte interdisciplinario de la retórica, México, unAm, 2001 (Bitácora de retórica, 14), pp. 329-354.

_., "Retórica de la comunicación y rétorica en sociedad", en Crisis de la historia. Condena de la política y desafíos sociales, México, unAm, 2009 (Bitácora de retórica, 25), pp. 39-58.

_, "El texto político de escritura periodística: la configuración retórica de su comunicación”, Círculo de Lingüística Aplicada a la Comunicación, 2000, pp. 3-12, consultado en: http://www.ucm.es/info/circulo/nol/albalade.htm (julio, 2011).

Assis DE Rojo, Estela, "Función del exemplum en la argumentación”, en Representaciones identitarias de la Roma antigua, Tucumán, Instituto Interdisciplinario de Literaturas Argentina y Comparada, Universidad Nacional de Tucumán, 2003, pp. 65-78.

AXER, Anna, "La dimensión retórica como forma de pensar el texto", en Los ejes de la retórica, México, UnAM, 2005 (Bitácora de retórica, 20), pp. 13-31.

CANDANo Fierro, Graciela, "Aproximaciones a una retórica del exemplum", en Ensayos sobre la tradición retórica, México, UNAM, 2005 (Bitácora de retórica, 20), pp. 225-236.

Coviello, Ana Luisa, La sátira romana: género de fronteras y antitexto en Horacio y Persio (tesis doctoral), Universidad de Barcelona, 2006, consultado en: http:// www.tesisenred.net/bitstream/handle/10803/1718/ALC_TESIS.pdf?sequence=1 (julio, 2011).

Chico Rico, Francisco, "La intellectio: notas sobre una sexta operación retórica", Castilla. Estudios de Literatura, 14, 1989, pp. 47-55.

DíEZ CORONADO, Marián, "El decoro según la teoría retórica de Quintiliano", en Actas del X Congreso Español de Estudios Clásicos, vol. II, Madrid, 2001, pp. 341346.

LÓPEZ EIRE, Antonio, Esencia y objeto de la retórica, México, unAM, 1996 (Bitácora de retórica, 4).

Martino, Luis Marcelo, "Reescribiendo la moral de los ancestros. Las costumbres ¿intachables? de los maiores en Tito Livio", Ágora. Estudos Clássicos em Debate, 12, 2010, pp. 49-69, consultado en: http://www2.dlc.ua.pt/classicos/4.martino.pdf (julio, 2011).

PujANTE, David, "El discurso político como discurso retórico. Estado de la cuestión", Retórica hoy. Teoría / Crítica, 5, 1998, pp. 307-336.

Ramírez Batalla, Miguel Ángel, "La actitud romana ante el pasado", Noua tellus, 25-2, 2007, pp. 231-272.

Reyes Coria, Bulmaro, "Preceptos viejos / modelos nuevos", Acta Poética, 29-1, primavera 2008, pp. 157-169.

Ruiz DE LA Cierva, Ma. del Carmen, "Los géneros retóricos desde sus orígenes hasta la actualidad", Rhêtorikê, 0, marzo de 2008, pp. 1-40, consultado en: http://dialnet.unirioja.es/servlet/autor?codigo=2731 (julio, 2011). 